\title{
Dry eye and refractive surgery, a citation network study
}

\section{Ojo seco y cirugía refractiva, estudio de red de citación}

\author{
Elena Fraga-Graells*, Cristina Alvarez-Peregrina, Cesar Villa-Collar, and Miguel A. Sanchez-Tena \\ School of Biomedical and Health Science, Universidad Europea de Madrid, Madrid, Spain
}

\begin{abstract}
Purpose: To identify the connections between the most cited researchers, and the impact of authors, journals, and subjects in the field of dry eye after refractive surgery, to focus future research on it. Methods: A search of "dry eye and refractive surgery" was made through Web of Science, and limiting the field for the article, keywords and abstract, and linked with the OR tab. The file obtained was analyzed later with CitNetExplorer ${ }^{\circledR}$ software obtaining an analysis of top-cited publications. A subnetwork analysis was made depending on the citations among them to identify clústeres and core publications. Results: This study showed 220 references in the period 1997 to 2019 that generated 675 citations across the network. The top 20 citations score has been published by the Journal of Cataract and Refractive Surgery and Journal of Refractive Surgery. Hovanesian, et al. tops the ranking of top-cited articles on dry eye and refractive surgery. Clustering and Core functions gave 2 clusters and 106 papers with at least four citations in the network, respectively. Conclusions: Current refractive surgery techniques are developed procedures, but often post-surgical complication is dry eye, that causes dissatisfaction and detriment to the patient's quality of life. Dry eye and refractive surgery are remarkable fields for researchers showing a prominent quantity of publications and connections among those. Expand knowledge in this field will serve to improve clinical applicability to decrease dry eye.
\end{abstract}

Keywords: Dry eye. Refractive surgery. Laser in situ keratomileusis. Citation network.

\section{Resumen}

Objetivo: Identificar las conexiones entre los investigadores más citados y el impacto de autores, revistas y contenidos en el campo de ojo seco tras cirugía refractiva, para focalizar la futura investigación en ello. Método: Se realizó una búsqueda de "ojo seco y cirugía refractiva" en Web of Science, y se limitó el campo para artículo, palabras clave y resumen, vinculados con "OR". El archivo resultante se analizó con el software CitNetExplorer ${ }^{\ominus}$ y se obtuvieron las publicaciones más citadas. Se realizó otro subanálisis sobre citaciones entre autores para identificar grupos y publicaciones principales. Resultados: Se hallaron 220 publicaciones entre 1997 y 2019 que generaron 675 citaciones en la red. Los 20 artículos más citados, encabezados por Hovanesain, et al., fueron publicados por Journal of Cataract and Refractive Surgery y Journal of Refractive Surgery. Mediante las funciones "cluster" y "core" se obtuvieron dos grupos y 106 artículos con al menos cuatro citas en la red, respectivamente. Conclusiones: Las técnicas actuales de cirugía refractiva son procedimientos avanzados y su complicación más frecuente es la aparición de ojo seco, que provoca insatisfacción y disminución de la calidad de vida de los pacientes. El ojo seco y la cirugía refractiva son un área destacada para los investigadores, con una cantidad significativa de publicaciones y conexiones entre ellos. Ampliar el conocimiento en este ámbito servirá para la mejora de aplicaciones clínicas con el fin de disminuir la aparición de ojo seco.

Palabras clave: Ojo seco. Cirugía refractiva. LASIK. Red de citación.

\section{Correspondence:}

*Elena Fraga-Graells

Tajo $\mathrm{s} / \mathrm{n}$

Date of reception: 19-06-2020

Date of acceptance: 21-06-2021

DOI: 10.24875/RMOE.M21000178
Available online: $05-11-2021$ Rev Mex Oftalmol (Eng). 2021;95(6):227-236

www.rmo.com.mx

E-mail: efraga @ serviciosoptometria.com

Published by Permanyer. This is an open access article under the CC BY-NC-ND license 2604-1731/@ 2021 Sociedad Mexicana de Oftalm (http://creativecommons.org/licenses/by-nc-nd/4.0/). 


\section{Introduction}

According to the Tear Film and Ocular Surface Society: "Dry eye is a multifactorial disease of the ocular surface characterized by a loss of homeostasis of the tear film, and accompanied by ocular symptoms, in which tear film instability and hyperosmolarity, ocular surface inflammation and damage, and neurosensory abnormalities play etiological roles"1. It is a broad and complex syndrome, and it can manifest symptoms of eye discomfort and visual disturbances from its mildest stage, even with potential injuries on the eye surface in the most severe cases. Its treatment may require environmental measures, tear substitutes, and/or pharmacological therapies.

Current refractive surgery techniques such as refractive lens exchange, photorefractive keratectomy (PRK), and laser in situ keratomileusis (LASIK), are highly developed procedures that have achieved high levels of efficacy, safety, and predictability. Their most frequent complication after surgery is dry eye. Although occur transiently it can become chronic and causes dissatisfaction and detriment to the patient's quality of life. Those techniques alter the ocular surface and the tear film homeostasis. LASIK is the most common procedure for refractive surgery. It influences postoperative tear film status affecting about $50 \%$ of patients within the first post-surgery week, $40 \%$ within the first post-surgery month, and between $20 \%$ and $40 \%$ after 6 months from their surgery ${ }^{2,3}$. Chronic dry eye symptoms a year after LASIK have a $0.8 \%$. incidence ${ }^{4}$. Among other reasons, corneal sensitivity, lacrimal gland, and blinking reflex loops after surgery may affect the quality and quantity of the tear film. Searching for new methods to improve the loss of neurotrophic effects at the post-surgery stage is currently the objective of several investigations. Therefore, to analyze differential diagnosis and to personalize the therapy to the patient, an exhaustive and critical appreciation of published results is essential.

A lot of researchers all around the world has been studied dry eye after refractive surgery, but it is unknown how these researchers and results are connected. A citation network analysis gives more simple and visual information, providing a better understanding of the research conducted in a specific field.

\section{Objective}

In this manuscript, the main connections between the most cited researchers are analyzed, getting a citation network to evaluate the impact of the different authors, journals, and subjects in the field of dry eye after refractive surgery. This citation network study gives the strength to simplify information and quantify the most relevant papers published. It also serves to create groups according to their connections, as well as their citations frequencies and clusters of study identification. The main aim was to identify all the aforementioned concepts to focus future research on it.

\section{Methods}

These bibliometric researches were defined as clustering publications, based on their citation relations, and analyze the results of the clustering at individual publications' level.

The bibliometric research was made through the website WEB OF SCIENCE (WoS), a Web technology-based platform that includes references of the main scientific publications of any discipline of knowledge since 1945. Using remote download techniques, papers published between 1997 and 2019 were selected. A search was carried out in English idiom with two free text words, "dry eye" as the first descriptor, and "refractive surgery" as the secondary one, both linked with the OR Boolean tab, and limiting the field for the article, keywords, and abstract. No other search limits were applied. The documentation search date was March 29, 2020. The file contains publications up to and including 2019. This is determined so that all the results for the entire year appear in the comparison analysis.

A file was downloaded from WoS and duplicated items were eliminated manually. A first review was carried out comparing author names and their number of publications per to year. A second verification review was carried out identifying publications with an equal number of citations and comparing their authors. Afterward, the file was analyzed using the CitNetExplorer ${ }^{\circledR}$ software. The software uses to visualize and analyze the most important publications in a specific field, showing the relationships that exist between them ${ }^{5}$.

To show the citations in the network in a period, a quantitative analysis was done. Internal connections among authors, journals, and subjects through the publications within the network, were studied by the attribute "citation score" of CitNetExplorer ${ }^{\circledR 6}$.

A subnetwork analysis was obtained using the "Cluster Function" that offers a list of differentiated groups or clusters according to the associations between them ${ }^{7}$.

Finally, the most important publications of the network were also analyzed using the function "core." This 


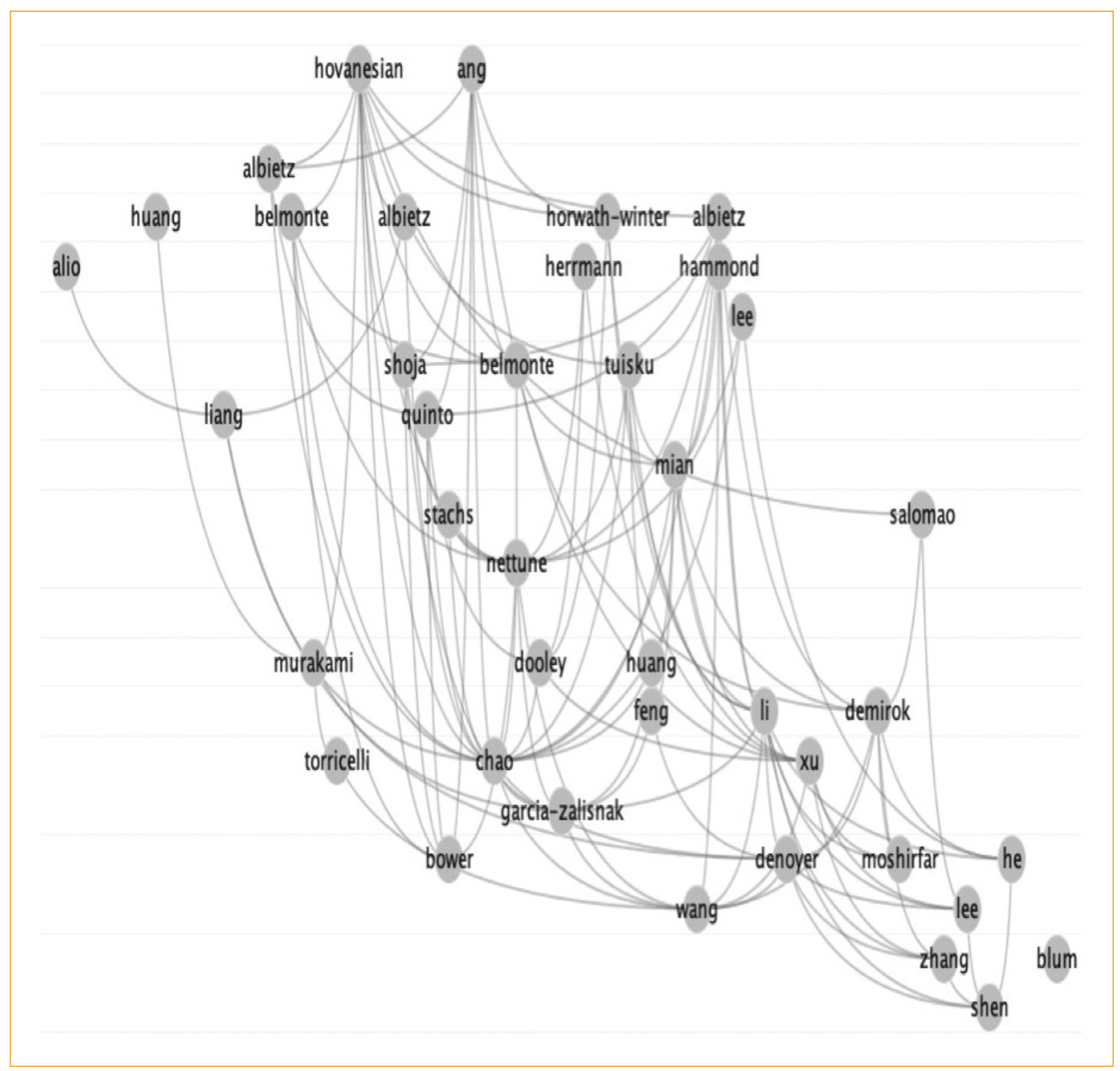

Figure 1. The top 20 cited publications in the dry eye and refractive network.

function gives the percentage of publications with four or more citations within the network.

\section{Results}

The network of dry eye and refractive surgery has 220 references, which generates 675 citations across the network, being 644 of these engendered from 2001 to the end of the search (representing 95\% of the total).

Regarding authors, Hovanesian et al. ${ }^{8}$ in 2001 tops the ranking of the most cited article on dry eye and refractive surgery, with a citation score of 42 . The article was entitled "Symptoms of dry eye and recurrent erosion syndrome after refractive surgery."

Figure 1 shows the network.

Table 1 shows as the top 20 citation score have been published mostly by the Journal of Cataract and Refractive Surgery and by the Journal of Refractive Surgery.

About the citations score of the top-20 cited articles, it extends from 42 to 9 . A total of only 3 top-cited (15\%) are not above average, and not refer to its articles about LASIK. These are Zhang, et al. ${ }^{22}$ with a SMILE technique and FS-LASIK meta-analysis, Bower, et al. ${ }^{4}$ with a PRK article, and Lee, etal. ${ }^{24}$ with a LASEK paper. Theircitations score is 12,11 , and 10 , respectively. 
Table 1. The top 20 cited publications from 1997 to 2019 in the dry eye and refractive surgery citation network

\begin{tabular}{|c|c|c|c|}
\hline Authors & Journal & Year & Cit. score \\
\hline Hovanesian et $\mathrm{al}^{8}$. & $\begin{array}{l}\text { Journal of Cataract } \\
\text { and Refractive Surgery }\end{array}$ & 2001 & 42 \\
\hline Denoyer et al ${ }^{9}$. & Ophthalmology & 2015 & 30 \\
\hline Li et $\mathrm{al}^{10}$. & Plos One & 2013 & 29 \\
\hline Ang et $\mathrm{al}^{11}$. & $\begin{array}{l}\text { Current Opinion in } \\
\text { Ophthalmology }\end{array}$ & 2001 & 26 \\
\hline Xu et $a^{12}$. & $\begin{array}{l}\text { Journal of Refractive } \\
\text { Surgery }\end{array}$ & 2014 & 23 \\
\hline Demirok et al ${ }^{13}$. & $\begin{array}{l}\text { Optometry and Vision } \\
\text { Science }\end{array}$ & 2013 & 22 \\
\hline Nettune et $\mathrm{al}^{14}$. & The Ocular Surface & 2010 & 20 \\
\hline Tuisku et $\mathrm{al}^{15}$. & $\begin{array}{l}\text { Journal of Refractive } \\
\text { Surgery }\end{array}$ & 2007 & 19 \\
\hline Albietz et al ${ }^{16}$. & $\begin{array}{l}\text { Journal of Cataract } \\
\text { And Refractive Surgery }\end{array}$ & 2004 & 18 \\
\hline Mian et al ${ }^{17}$. & $\begin{array}{l}\text { Cataract and Refractive } \\
\text { Surgery }\end{array}$ & 2009 & 17 \\
\hline Chao et al ${ }^{18}$. & The Ocular Surface & 2014 & 16 \\
\hline Shoja et $\mathrm{al}^{3}$. & $\begin{array}{l}\text { European Journal of } \\
\text { Ophthalmology }\end{array}$ & 2007 & 15 \\
\hline Quinto et al ${ }^{19}$. & $\begin{array}{l}\text { Current Opinion In } \\
\text { Ophthalmology }\end{array}$ & 2008 & 14 \\
\hline Belmonte et $\mathrm{al}^{20}$. & $\begin{array}{l}\text { Experimental Eye } \\
\text { Research }\end{array}$ & 2004 & 13 \\
\hline Belmonte $\mathrm{C}^{21}$. & $\begin{array}{l}\text { Journal } \\
\text { of Refractive Surgery }\end{array}$ & 2007 & 12 \\
\hline Zhang et $\mathrm{al}^{22}$. & $\begin{array}{l}\text { Journal of Refractive } \\
\text { Surgery }\end{array}$ & 2016 & 12 \\
\hline Moshirfar et al ${ }^{23}$. & $\begin{array}{l}\text { Journal of Cataract } \\
\text { and Refractive Surgery }\end{array}$ & 2015 & 11 \\
\hline Bower et al ${ }^{4}$. & $\begin{array}{l}\text { Journal of Cataract } \\
\text { And Refractive Surgery }\end{array}$ & 2015 & 11 \\
\hline Lee et $\mathrm{al}^{24}$. & $\begin{array}{l}\text { American Journal of } \\
\text { Ophthalmology }\end{array}$ & 2006 & 10 \\
\hline Albietz et $\mathrm{al}^{25}$. & $\begin{array}{l}\text { Journal of Refractive } \\
\text { Surgery }\end{array}$ & 2004 & 9 \\
\hline
\end{tabular}

About the journals in which the top-20 cited papers have been published, five of them have been published in "Journal of Refractive Surgery" and other five in "Journal of Cataract and Refractive Surgery." "Current Opinion in Ophthalmology" follows them with two publications. No other journal published more than one paper.

\section{Clusters}

The clustering function gives two clusters detailed as follow:

- Cluster 1, with 138 publications $(62 \%$ of the total network). It contains 558 citations ( $82 \%$ of the total network) from 2001 to 2017. These publications are about the etiology of dry eye induced by LASIK. The top 20 most cited in the network coincide in appearance and order with the 20 most cited in this subnetwork. Hovanesian, et al. tops this ranking with his publication in the Journal of Cataract and Refractive Surgery, in $2001^{8}$. In the top-40 of this cluster, only six and four publications were also specifically referred to corneal sensation and innervation, and 4, 6, and 3 were referring to SMILE, Femtosecond laser, and PRK techniques, respectively. The most common journals were "Journal of Refractive surgery" with eight papers, "Journal of Cataract and Refractive Surgery" with 7, and "Current Opinion in Ophthalmology" with 3 publications. The most productive years were 2015 and 2014 with 6 publications per year, and 2004 and 2013 with 4 publications per year.

- Cluster 2, with 26 publications ( $11 \%$ of the total network). It contains 55 citations ( $8 \%$ of the total network) from 2005 to 2019. These publications are about refractive surgery and other conditions related to dry eye, as Sjögren syndrome, allergy or rheum, or other post-operative treatments as cyclosporine for dry eye management. Liang, et al. tops the ranking with his publication in Cornea, in 2008, and with a citation score of $9^{26}$. The most productive years were 2019 with 5 publications per year, followed by 2014 with 4, and 2016, 2013 and 2008 with 3 publications per year.

The remaining 56 publications are not associated with each other, so they do not belong to any cluster.

Figures 2 and 3 show every cluster's connections.

The years with most publications in the top 40 of cluster 1 subnetwork were 2014 and 2015, with 6 per year, following by 2004 with four, and 2007, 2010, and 2013 with 3 per year. Figure 4 shows the number of publications per year of the top 26 papers of each cluster.

\section{Core publications}

Core Function gives 106 papers with at least four citations in the network, which represents a $47.92 \%$. Hovanesian, et al., from cluster 1, appears in the first position, and Liang, et al. the top-cited from cluster 2, is in the $21^{\text {st }}$ position. 44 publications of cluster 


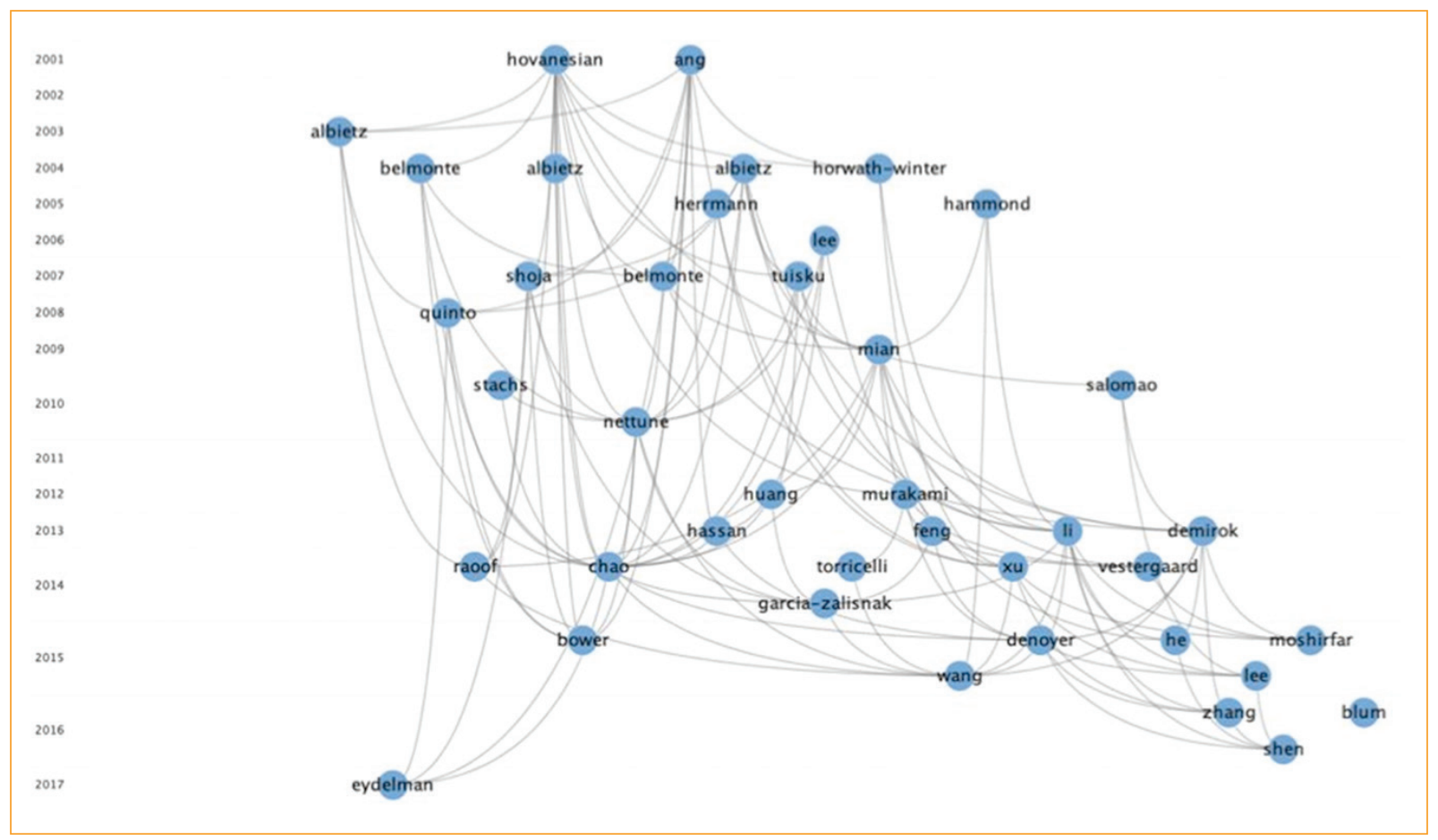

Figure 2. Top 40 cited articles of cluster 1 subnetwork.

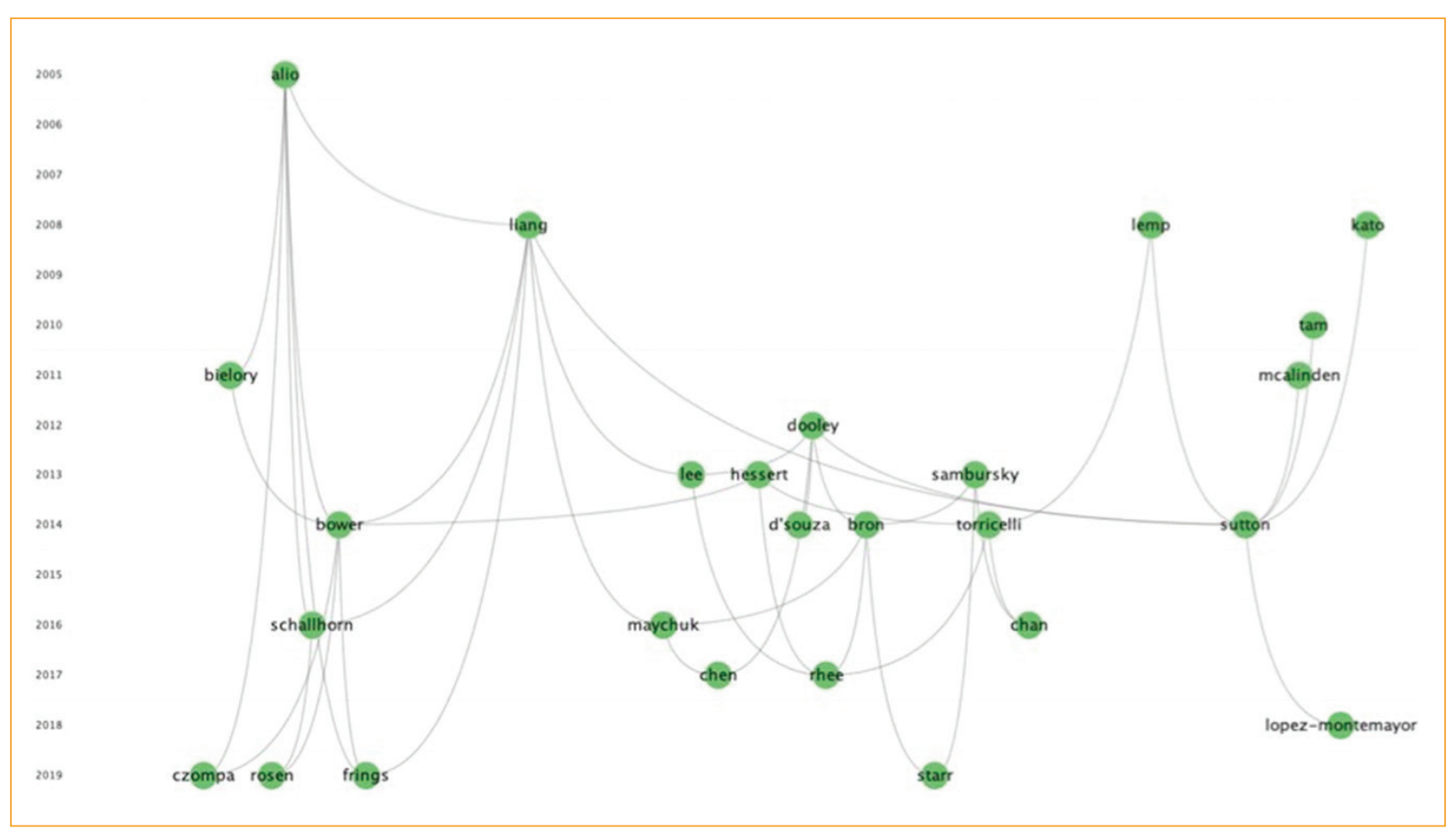

Figure 3. Cluster 2 subnetwork.

$1(31.88 \%)$ and 14 publications of cluster $2(53.84 \%)$ do not appear in the Core results because they have less than 4 citations. Figure 5 shows the Core Function results.

\section{Discussion}

Dry eye is one of the most prevalent ophthalmic diseases affecting the patient's quality of life. It is also one 


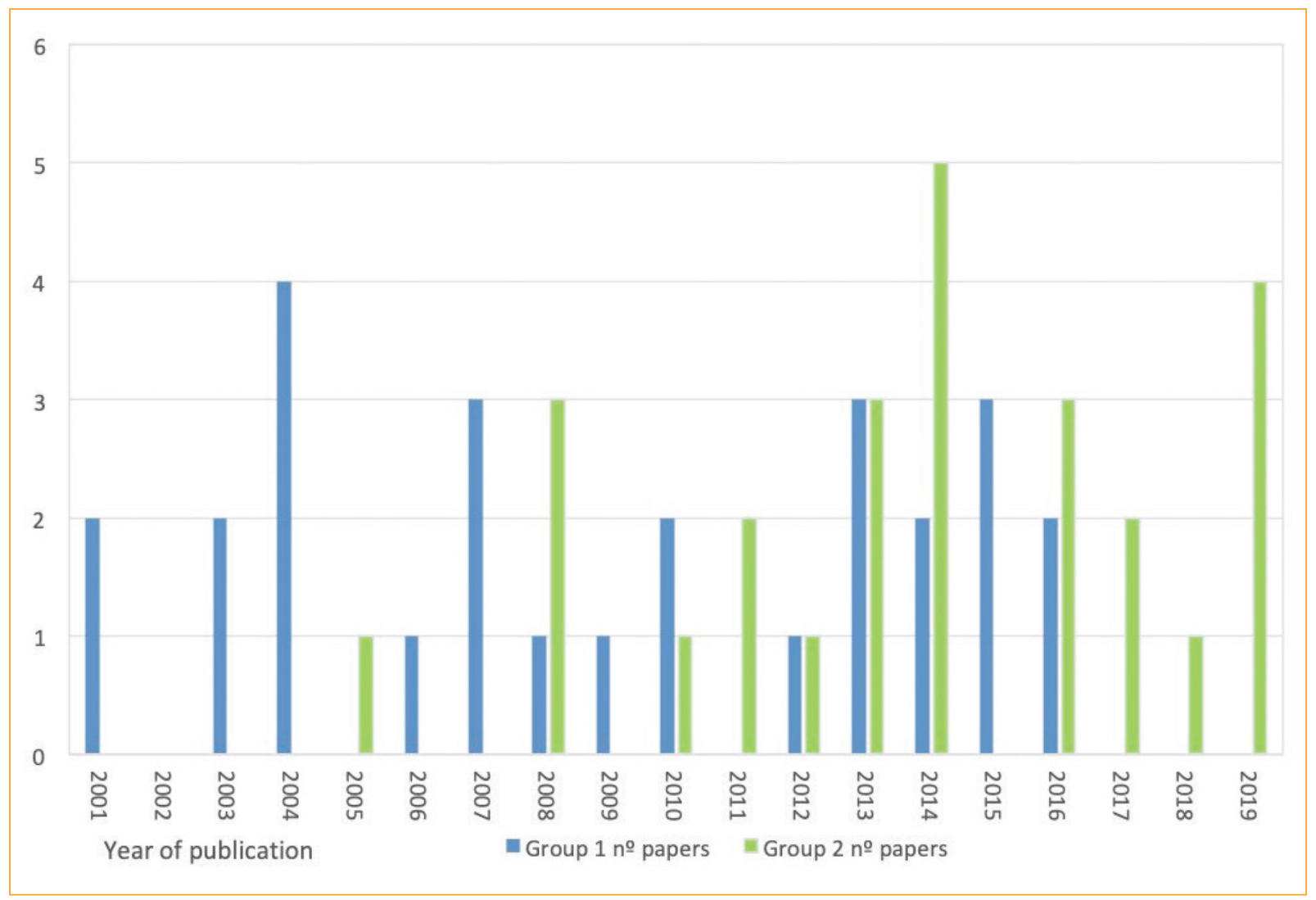

Figure 4. Number of publications per year of the top 26 paper of each cluster.

of the most common complications after refractive surgery.

This study provides information on clustering publications based on the citations network. It permits to analyze the results of the most important publications about dry eye after refractive surgery. The network starts in 1997, because it is the year of the first publication that refers to "dry eye" and "refractive surgery" and finishes in 2019. As far as the PRK technique appeared in 1980 and LASIK in 1990, it can be assumed that there were no publications regarding dry eye and refractive surgery until the incidence of signs and symptoms of dry eye were widely observed in enough number of surgery cases. No other publications before 1997 were found except one from 1995 by Lemp ${ }^{27}$. The author's name, journal, and year of that publication appeared in the WoS search, but the title was not available, so it was eliminated by not having enough details. This circumstance may cause a bias of results in the study conducted, which may also be repeated in future studies on the same topic.

The top-20 cited papers in the network were published from 2001 to 2016 recognizing five different stages. These five phases indicate the different topics studied and how research in the field of dry eye and refractive surgery has evolved. The first stage occupies 2001 with two publications Hovanesian, et al. ${ }^{8}$ and Ang, et $\mathrm{al}^{11}$. The Hovanesian, et al. article studied that the incidence and severity of dry eye in 1731 patients who had had primary myopic PRK or LASIK at least 6 months previously. These authors concluded that dry eye symptoms occurred commonly after LASIK but were significantly more severe and prolonged after PRK. The Ang, et al. article studied how LASIK and PRK can induce or exacerbate dry eye after surgery. This author concluded that patients should be warned about dry eye complications after surgery, and how the use of artificial tears and punctual plugs is helpful to prevent or alleviate patient's ocular discomfort.

The second stage, from 2002 to 2003, has no publications.

The third stage, from 2004 to 2010 , contains the two most productive years, 2004 and 2007 with three publications per year. In 2004, there were two publications by Albietz, et al; Albietz and Lenton ${ }^{16,25}$ and one publication more by Belmonte, et al. ${ }^{20}$ The Albietz, et al. 


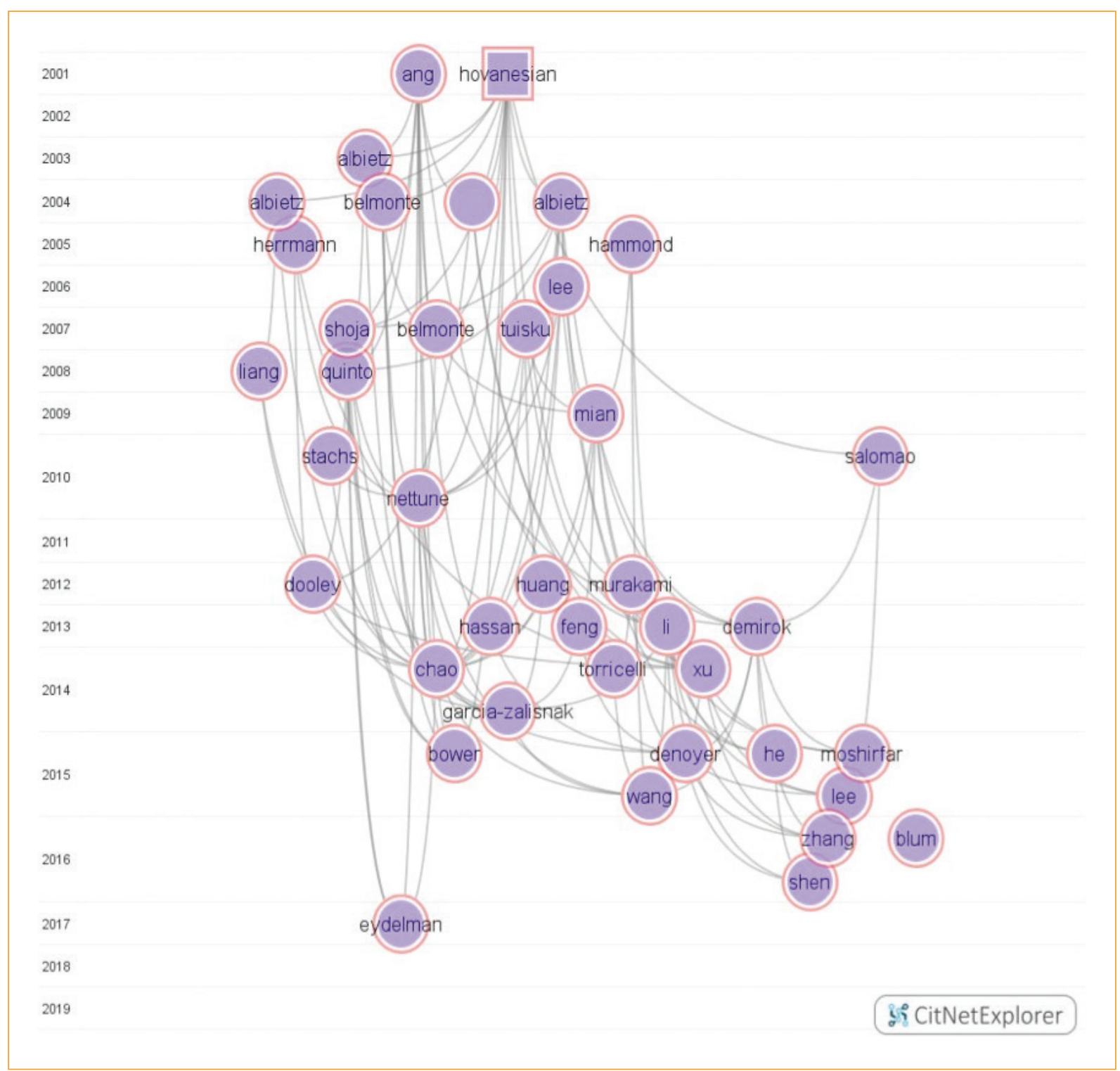

Figure 5. Core Function results of the dry eye and refractive surgery network.

article studied the relationship between chronic dry eye and refractive regression after LASIK and concluded that it was increased in patients with chronic dry eye ${ }^{16}$. The Albietz, et al. article is a review of the evidence-based recommendations for best practice management strategies in patients suffering dry eye before, during, and after LASIK ${ }^{25}$. Finally, Belmonte, et al. article studied the neural basis of cornea and conjunctiva sensations following refractive surgery. The authors concluded that the altered excitability was the origin of lowered sensitivity, spontaneous pain, and dry eye sensations following refractive surgery ${ }^{20}$. In 2007, we found three papers by Tuisku, et al..$^{15}$ Shoja and Besharati ${ }^{3}$ and Belmonte ${ }^{21}$. Tuisku, et al. studied 20 patients who had undergone high myopic LASIK and compared results with a control group. They did not find demonstrable differences ${ }^{15}$. Shoja, et al. studied the incidence and risk factors of dry eye after myopic LASIK, concluding that these patients developed dry eye with compromised tear function at least 6 months after surgery. Authors found a higher risk to suffer from dry eye in patients that required higher refractive correction ${ }^{3}$. The Belmonte article on the remarked the cornea innervation by functional types of sensory nerves. The authors explained as when sensory nerves are stimulated, they evoke sensations as ocular dryness, discomfort, and pain. They concluded that drugs that reduce abnormal activity in injured corneal nerves might represent a 
therapeutic alternative for eye dryness sensations after refractive surgery.

A transition stage occupies the years 2011 and 2012 without publications.

The final stage comes from 2013 to 2015, with 2015 as the most productive year. In 2015 were publications with a citation score of 30,11 , and 11 too, by Denoyer, et al ${ }^{9}$. Moshirfar et al. ${ }^{23}$ and Bower, et al., ${ }^{4}$ respectively. The Denoyer, et al. article studied the comparison between small incision lenticule extraction (SMILE) and LASIK for post-refractive dry eye disease. The author concluded that SMILE has less impact on the ocular surface and corneal innervation compared with LASIK, further reducing the incidence of dry eye disease. The Moshirfar, et al. article reviewed benefits, limitations, and future applications of SMILE procedure from 56 articles from the PubMed database. The Bower, et al. article evaluated dry eye manifestations after PRK and LASIK to determine the incidence and predictive factors of chronic dry eye using a set of dry-eye criteria. The authors concluded that ocular surface and tear film characteristics during pre-operative examination might help to predict chronic dry-eye development after those surgeries. The third and fifth stages highlight the great relevance of the dry eye and refractive surgery research in recent dates. In summary, research about refractive surgery and dry eye begins studying symptoms and signs of dry eye after surgery. It continues with the study of the corneal nervous structure, hypothesizing that dry eye is caused by the amputation of the nerves at the surgery process; and ends with the study of new techniques that reduce the biomechanical resistance of the cornea, as intended the SMILE technique, by preserving Bowman membrane at surgery process.

In a previous citation network study regarding the dry eye, Sanchez-Tena, et al. ${ }^{28}$ found a cluster about refractive surgery. The most cited article in this cluster was a review from Ambrosio, et al. ${ }^{29}$ published in 2008 in the Journal of Refractive Surgery. They reviewed the scientific literature and summarized the experience of the authors to propose methods for decreasing dry eye after refractive surgery. In our network citation study focusing on dry eye and refractive surgery, that author appears in position 3 with a citation score of 41 . The difference might be due to the aforementioned study was limited to 10-years publications (2007-2018). In our study, we have analyzed the whole scientific publications from the first refractive surgery time.

A large part of the references selected refer to LASIK technique, but no distinction was made in the search by type of surgery. In the period analyzed, the largest number of interventions has been performed with the LASIK technique.

About the most related surgical procedures of the top-20 cited articles, only 3 top-cited not refer to their articles about LASIK. This situation agrees with the reality of the clinic, where LASIK is the most common technique around the world. Another explication could be that LASIK produces a significant reduction in tear production with respect to other refractive surgery techniques ${ }^{30}$.

About the main journals in which the top-20 cited papers have been published, "Journal of Refractive Surgery," "Journal of Cataract and Refractive Surgery," and "Current Opinion in Ophthalmology," this data offer no doubt. These results are expected because these journals are the most important in the refractive surgery field, although all three journals are American. This could be a result of a database limitation due to its preferences for journals using this language.

Regarding clusters, two relevant groups were clearly defined. Cluster 1 was the biggest, and the etiology of dry eye induced by LASIK was the wieldiest topic studied. Cluster 2, which was $81 \%$ smaller than cluster 1 , was about refractive surgery and other conditions related to dry eye. It was also referred to dry eye syndrome as the principal point of the study. Both clusters are differentiated by the focus of the study and the periods of publications. The size difference between both clusters might be due to the great number of surgeries performed by LASIK. Since LASIK debuted until today, tens of millions of surgeries had been performed worldwide, much more than PRK interventions; in contrast, SMILE technique began to be used in Europe in 2012 and did not receive FDA approval until 2016. The Carl Zeiss Meditec Company, proprietary of VisuMax femtosecond laser for SMILE surgery celebrated 1 million of procedures made in September 2017.

Core publications account for a high percentage $(47.92 \%)$ in the network. This means that there is a strong focus on the research carried out in this field. Dry eye management induced by LASIK is represented in this core. Although in less number, other surgery techniques and dry eye conditions are also represented. The evolution of LASIK using a mechanical microkeratome to create the flap, to the use of a laser femtosecond to create it, occurred to get greater predictability of flap depth and higher precision in its thickness, looking for less ocular and visual complications later. Likewise, improvements in PRK to LASEK and Trans-PRK technique have also provided higher 
predictability and best post-surgery conditions. Into these Core publications, studies and researches that have favored these mentioned evolutions are represented. But the common goal for them has been to achieve improvements for dry eye at post-surgery stages. One way was the strategy of look for procedures that respect the hardest structures of the cornea such as the stroma and Bowman's membrane, as is the case of SMILE technique. Another way was to investigate the ocular surface at pre-surgery that could predict dry eye after it.

Bibliographic databases are the main source of information used in bibliometric studies. Having chosen WoS among other available databases may lead to information bias. The Institute for Scientific Information databases was the first to allow bibliometric work, being WoS the only international and multidisciplinary tool available accessing to the literature of several disciplines of science for four decades ago. The Journal Citation Report is made including WoS journals as citators, and publishing their impact factor. WoS is a traditional useful tool for searching bibliographic, although it also has limitations; some of these being improved by Scopus database (Elsevier, 2004) that currently indexes more peer-reviewed (SCImago Journal Rank, 2015) than WoS. Although greater Scopus coverage contributes to the advantage of containing a greater number of citations; nevertheless, it loses strength for references before 1996. This circumstance was of interest for our study because we were searching for the most extensive temporal bibliography. Another circumstance was necessary for our study to select WoS database. WoS emphasizes the quality of its content, rather than quantity. This is a circumstance that is satisfied if we recall Bradford's Law, which postulates that most of the important scientific publications are found in a small number of journals; although this feature has been found fault with favoring American English idiom for scientific literature. As far as we know, no studies have been conducted comparing WoS and Scopus databases in the field of dry eye. We consider this study as the first part of future comparison.

\section{Conclusions}

Dry eye and refractive surgery are a very remarkable field for researchers, with a wide number of publications and connections among them.

This study provides knowledge in refractive surgery that will serve to improve clinical applicability to decrease dry eye.

\section{Funding}

This research received no external funding neither sponsors.

\section{Conflicts of interest}

The authors declare no conflict of interest.

\section{Ethical disclosures}

It is a literature review bibliometric study; therefore, there is no interventions in patients.

Protection of human and animal subjects. The authors declare that no experiments were performed on humans or animals for this study.

Confidentiality of data. The authors declare that no patient data appear in this article.

Right to privacy and informed consent. The authors declare that no patient data appear in this article.

\section{References}

1. Craig JP, Nichols KK, Akpek EK, Caffery B, Dua HS, Joo CK, et al. TFOS DEWS II definition and classification report. Ocul Surf. 2017;15:276-83.

2. De Paiva CS, Chen Z, Koch DD, Hamill MB, Manuel FK, Hassan SS, et al. The incidence and risk factors for developing dry eye after myopic LASIK. Am J Ophthalmol. 2006;141:438-45.

3. Shoja MR, Besharati MR. Dry eye after LASIK for myopia: incidence and risk factors. Eur J Ophthalmol. 2007:17:1-6.

4. Bower KS, Sia RK, Ryan DS, Mines MJ, Dartt DA. Chronic dry eye in photorefractive keratectomy and laser in situ keratomileusis: manifestations, incidence, and predictive factors. J Cataract Refract Surg. 2015;41:2624-34.

5. CitNetExplorer@: analyzing Citation Patterns in Scientific Literature; 2019. Available at: http://www. citnetexplorer.nl. [Last accessed on 2019 Feb 08].

6. Van Eck NJ, Waltman L. CitNetExplorer: a new software tool for analyzing and visualizing citation network. J Inform. 2014;8:802-23.

7. Van Eck NJ, Waltman L. Citation-based clustering of publications using CitNetExplorer and VOSviewer. Sci Tometr. 2017;111:1053-70.

8. Hovanesian JA, Shah SS, Maloney RK. Symptoms of dry eye and recurrent erosion síndrome after refractive surgery. J Cataract Refract Surg 2001;27:577-84

9. Denoyer A, Landman E, Trinh L, Faure JF, Auclin F, Baudouin C. Dry eye disease after refractive surgery: comparative outcomes of small incision lenticule extraction versus LASIK. Ophthalmology. 2015;122:669-76.

10. Li M, Zhao J, Shen Y, Li T, Xu H, Yu Y, et al. Comparison of dry eye and corneal sensitivity between small incision lenticule extraction and femtosecond LASIK for myopia. PLoS One. 2013;8:e77797.

11. Ang RT, Dartt DA, Tsubota K. Dry eye after refractive surgery. Curr Opin Ophthalmol. 2001;12:318-22.

12. Xu Y, Yang Y. Dry eye after small incision lenticule extraction and LASIK for myopia. J Refract Surg. 2014;30:186-90.

13. Demirok A, Ozgurhan EB, Agca A, Kara N, Bozkurt E, Cancaya KI, et al. Corneal sensation after corneal refractive surgery with small incision lenticule extraction. Optom Vis Sci. 2013:90:1040-7.

14. Nettune GR, Pflugfelder SC. Post-LASIK tear dysfunction and dysesthesia. Ocul Surf. 2010;8:135-45.

15. Tuisku IS, Lindbohm N, Wilson SE, Tervo TM. Dry eye and corneal sensitivity after high myopic LASIK. J Refract Surg. 2007;23:338-42.

16. Albietz JM, Lenton LM, McLennan SG. Chronic dry eye and regression after laser in situ keratomileusis for myopia. J Cataract Refract Surg. 2004;30:675-84.

17. Mian S, Li AY, Dutta S, Musch DC, Shtein RM. Dry eyes and corneal sensation after laser in situ keratomileusis with femtosecond laser flap creation effect of hinge position, hinge angle, and flap thickness. J Cataract Refract Surg. 2009;35:2092-8.

18. Chao C, Golebiowski B, Stapleton F. The role of corneal innervation in LASIK-induced neuropathic dry eye. Ocul Surf. 2014;12:32-45. 
Rev Mex Oftalmol (Eng). 2021;95(6)

19. Quinto GG, Camacho W, Behrens A. Postrefractive surgery dry eye. Curr Opin Ophthalmol. 2008;19:335-41.

20. Belmonte C, Acosta MC, Gallar J. Neural basis of sensation in intact and injured corneas. Exp Eye Res. 2004;78:513-25.

21. Belmonte $\mathrm{C}$. Eye dryness sensations after refractive surgery: impaired tear secretion or "Phantom" cornea? J Refract Surg. 2007;23:598-602.

22. Zhang $Y$, Shen $Q$, Jia $Y$, Zhou D, Zhou J. Clinical outcomes of SMILE and FS-LASIK used to treat myopia: a meta-analysis. J Refract Surg. 2016;32:256-65

23. Moshirfar M, McCaughey MV, Dan BS, Reinstein Z, Shah R, Santiago-Caban L. Small-incision lenticule extraction. J Cataract Refract Surg. 2015;41:652-65

24. Lee SJ, Kim JK, Seo KY, Kim EK, Lee HK. Comparison of corneal nerve regeneration and sensitivity between keratomileusis (LASEK). Am J Ophthalmol. 2006;141:1009-15.
25. Albietz JM, Lenton LM. Management of the ocular surface and tear film before, during, and after laser in situ Keratomileusis. J Refract Surg. 2004;20:62-71.

26. Liang L, Zhang M, Zou W, Liu Z. Aggravated dry eye after laser in situ keratomileusis in patients with Sjögren síndrome. Cornea. 2008;27:120-3.

27. Lemp MA. Report of the national eye institute/industry workshop on clinical trials in dry eyes. CLAO J. 1995;21:221-32.

28. Sanchez-Tena MA, Alvarez-Peregrina C, Villa-Collar C. Dry eye analysis: a citation network study. J Ophthalmol. 2019;2019:3048740.

29. Ambrosio R, Tervo T, Wilson SE. LASIK-associated dry eye and neurotrophic epitheliopathy: pathophysiology and strategies for prevention and treatment. J Refract Surg. 2008;24:396-407.

30. Sambhi RS, Shambh GD, Mather R, Malvankar-Mehta MS. Dry eye after refractive surgery: a meta-analysis. Can J Ophthalmol. 2019;55:99-106. 